\title{
USO DE BIOFILTRO AERADO SUBMERSO COM MATERIAL SUPORTE ALTERNATIVO PARA O TRATAMENTO DE EFLUENTE VINÍCOLA: SISTEMA EM BATELADA
}

\section{THE USE OF THE AEROBIC SUBMERGED BIOFILTER IN THE TREATMENT OF WINE EFFLUENT: SYSTEM IN BATCH}

\section{Pétrick Anderson Soares ${ }^{1}$; Evelyn Zucco'; Sandra Denise Camargo Mendes ${ }^{2}$}

${ }^{1}$ Engenheiros Ambientais, Mestrandos em Engenharia Ambiental, Universidade
Regional de Blumenau (FURB). Bolsistas Capes.
${ }^{2}$ Pesquisadora da Empresa de Pesquisa Agropecuária e Extensão Rural de Santa Catarina - EPAGRI.

\section{RESUMO}

Neste trabalho foi avaliado o uso potencial do Biofiltro Aerado Submerso (BAS) no tratamento de efluente vinícola. A utilização do meio suporte de rolhas de cortiça visou testar o reuso deste material, com o objetivo de minimizar o custo de implantação de uma estação de tratamento de efluentes. A unidade instalada, em escala laboratorial, apresentou médias de remoção de demanda química de oxigênio (DQO), sólidos suspensos e turbidez de $78,5 \%, 60,1 \%$ e $82,8 \%$, respectivamente. O reator operou com tempo de detenção hidráulica de 48 horas e a alimentação ocorreu com carga orgânica de $1,73 \mathrm{~kg}$.DQO. $\mathrm{m}^{3} \mathrm{~d}^{-1}$. Foi constatado que o emprego do BAS como apresenta-se uma alternativa vantajosa, bem como o uso das rolhas de cortiças como material suporte no tratamento de efluentes vinícolas.

Palavras-chave: Biofiltro aerado submerso. Efluente vinícola. Material suporte alternativo. Tratamento de efluentes. Reutilização de materiais.

\footnotetext{
ABSTRACT

This study was evaluated the potential use of Submerged Aerated Biofilter (ASB) in the winery effluent treatment. The use of the support of corks stoppers angle for to test the reuse of this material, in order to minimize the deployment cost
} 
of a sewage treatment plant effluent. The unit installed in a laboratory scale, showed average removal of chemical oxygen demand (COD), suspended solids and turbidity of $78,5 \%, 60,1 \%$ and $82,8 \%$ respectively. The reactor was operated with hydraulic retention time of 48 hours and feeding occurred with the organic load of 1,73 kg.COD. $\mathrm{m}^{3} \mathrm{~d}^{-1}$. It was noted that the use of ASB presents an advantageous alternative, as well as the use of cork stoppers as support material in wineries effluent treatment.

Keywords: Aerated biofilter. Wine effluent. Material support alternative. Effluent treatment. Materials' Reuse.

\section{INTRODUÇÃO}

O setor vinícola apresenta-se como uma atividade de elevada expressão sócioeconômica, principalmente nos estados do Rio Grande do Sul e Santa Catarina. A produção de vinho em Santa Catarina, em cantinas instaladas em pequenas propriedades rurais, é responsável por $5 \%$ da produção nacional (15,4 milhões de litros). A região do Vale do Rio do Peixe é a região de maior concentração de uvas e cantinas, nas quais utilizam uva comum para a fabricação de vinhos de mesa, representando mais de $60 \%$ da produção estadual (BRITO, 2007).

$\mathrm{Na}$ atividade vinícola há um uso intensivo da água em todo o sistema, desde o início do processo, nas operações de prensagem e esmagamento, até a elaboração dos produtos finais. Esta água, após seu uso no processo, gera um efluente industrial, o qual é composto de outros resíduos derivados do processo, como resíduos de subprodutos (engaços, sementes, cascas, tartaratos, borras), e produtos utilizados para o tratamento do vinho como bentonita e terras diatomáceas para filtração. O efluente gerado sai com carga orgânica elevada e com um grande potencial poluidor, necessitando de um tratamento antes de ser lançado ao corpo hídrico.

Com a produção de vinhos em larga escala, produtores e indústrias da área vinícola enfrentam o problema do descarte do efluente gerado na produção do mesmo. Esse efluente possui um processo de fermentação que ocorre durante algum tempo, após sua remoção da vinícola. São gerados uma série de compostos tóxicos, como ácidos graxos, ésteres, mercaptanas, fenóis e polifenóis, podendo afetar diretamente os microrganismos e vida aquática, constituindo-se em fonte potencial de poluentes ambientais (BORIES et al., 2007).

O Biofiltro Aerado Submerso (BAS) surge como alternativa para sistemas de tratamento, com alto grau de eficiência, baixo custo de implantação e de operação, se comparado com os tradicionais sistemas de tratamento como, por exemplo, o lodo ativado. Principalmente se a vinícola almeja um crescimento na área turística, pois evita possíveis constrangimentos com mau cheiro ou impacto visual.

O BAS consiste de um leito contendo um meio altamente permeável, cujos microrganismos fixam-se formando um filme biológico. Através deste leito o efluente a ser tratado é depurado. O meio filtrante consiste geralmente de pedras, carvão 
ativado, cavacos de madeira e uma variedade de materiais plásticos. No biofilme a matéria orgânica é degradada por uma população de microrganismos aderidos ao meio filtrante (JORDÃO e PESSOA, 1995; TEIXERA, 2006).

Diante da exposição acima, este trabalho, tem como objetivo em pequena escala determinar o uso potencial do BAS no tratamento de efluentes oriundos da indústria vinícola, como alternativa de baixo custo de implantação e operação.

\section{MATERIAL E MÉTODO}

2.1. Descrição e alimentação da unidade de pesquisa

O reator experimental foi instalado no Laboratório de Análises de Bebidas e Vinagres da Empresa de Pesquisa Agropecuária e Extensão Rural de Santa Catarina EPAGRI, na cidade de Videira - SC. O reator foi instalado em escala laboratorial e seu sistema de vazão ocorria em batelada. O volume útil do reator foi definido através do deslocamento do líquido: o material suporte foi colocado no reator preenchido com água (4,5 litros) e o volume de água deslocado para fora do reator (após a colocação do material) representava o volume ocupado pelo meio filtrante. A unidade é composta por material plástico, tendo como capacidade de volume 5,0 L, fluxo ascendente e duas alimentações de oxigênio dissolvido como demonstra a Figura 1.

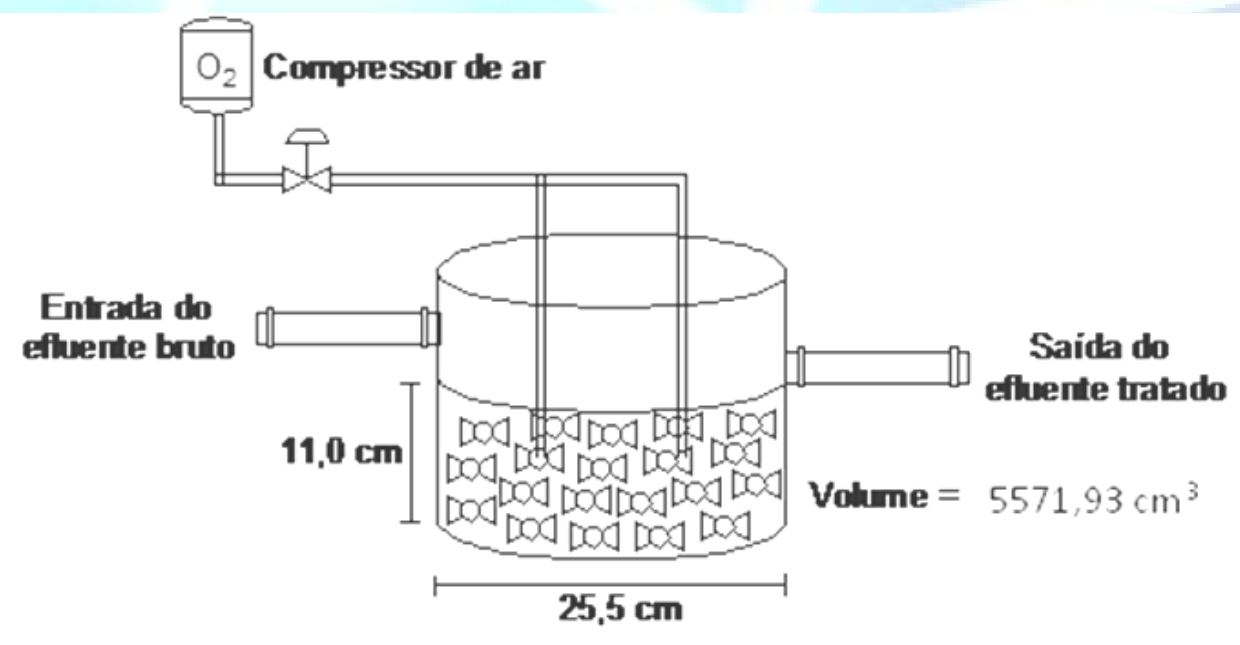

DOO Meio Suporte - Rolhas de cortiça

Figura 1. Unidade de biofiltro aerado submerso

O meio suporte era composto por rolhas de cortiças com massa especifica de $0,25 \mathrm{~g} \mathrm{~cm}^{-3}$. As rolhas de cortiça sofreram um processo de raspagem a fim de aumentar a sua rugosidade e assim o seu potencial de agregar o biofilme. O sistema de aeração era composto por duas pedras do tipo porosas, quatro separadores e um aerador com potência equivalente a $100 \mathrm{~L} \mathrm{~h}^{-1}$. 
O substrato do BAS foi o efluente oriundo de uma indústria vitivinicultura, localizada no município de Iomerê, região do alto vale do rio do Peixe - Santa Catarina - Brasil. O efluente utilizado foi coletado durante dias normais de produção da vinícola, na safra de 2008.

\subsection{Monitoramento}

O monitoramento do afluente foi baseado nos seguintes parâmetros: $\mathrm{pH}$, temperatura, alcalinidade, turbidez, cor verdadeira, amônia, nitrito, fósforo reativo, DQO, sólidos suspensos, condutividade (APHA, 2001) e índice de cor, com comprimentos de onda: 420, 520, $620 \mathrm{~nm}$ (RIBÉREAU-GAYON et al., 2004). As análises foram realizadas em período de 24 e 48 horas.

Diariamente foi coletado um volume de $50 \mathrm{~mL}$ da superfície do reator e realizadas as análises de $\mathrm{pH}$ e temperatura. $\mathrm{O}$ oxigênio dissolvido foi monitorado para avaliar a eficiência do sistema de aeração na superfície do líquido dos reatores, utilizando-se um oxímetro (VWR Scientific modelo 4000).

$\mathrm{O}$ método utilizado para a determinação de antocianinas totais foi o método $\mathrm{pH}$ diferencial, descrito por Ribéreau-Gayon et al., (2004). Utilizando-se espectrofotômetro UV - Visível (modelo DR/2010, HACH) para as medidas de absorbâncias $(550 \mathrm{~nm})$ das amostras. Após, foi calculada a concentração de antocianinas totais equivalentes, em $\mathrm{mg} \mathrm{L}^{-1}$.

A determinação dos taninos totais baseia-se na propriedade das protocianidinas monoméricas ou polimerizadas de originarem antocianinas totais por aquecimento em meio ácido. $\mathrm{O}$ método fundamenta-se na transformação das leucoantocianinas totais em antocianinas totais através da hidrólise ácida (RIBÉREAU-GAYON et al., 2004).

O conteúdo de polifenóis totais foi determinado nas amostras de efluentes por espectrofotometria, de acordo com o método colorimétrico de Folin-Ciocalteu, (TOMASSET, 1998). O reagente de Folin-Ciocalteu, constituído de ácido fosfotúngstico $\left(\mathrm{H}_{3} \mathrm{PW}_{12} \mathrm{O}_{40}\right)$ e de ácido fosfomolíbdico $\left(\mathrm{H}_{3} \mathrm{PMo}_{12} \mathrm{O}_{40}\right)$, ao oxidar os fenóis, se reduz a óxido de tungstênio $\left(\mathrm{W}_{8} \mathrm{O}_{23}\right)$ e de molibdênio $\left(\mathrm{Mo}_{8} \mathrm{O}_{23}\right)$, de cor azul. Utilizando se espectrofotômetro UV - Visível (modelo DR/2010, HACK) a 760 $\mathrm{nm}$ foram realizadas leituras das absorbâncias das amostras. Os valores obtidos foram expressos em $\mathrm{mg} \mathrm{L}^{-1}$ equivalentes de catequina.

\section{RESULTADOS E DISCUSSÃO}

O índice de cor foi avaliado para caracterizar uma eventual mistura indevida no momento da alimentação do reator entre o volume afluente e efluente. Em três dias de alimentação ocorreram mistura, dia 32, 66 e 88, onde o índice de cor do efluente foi superior aos valores obtidos para o afluente, conforme observado na Figura 2. 


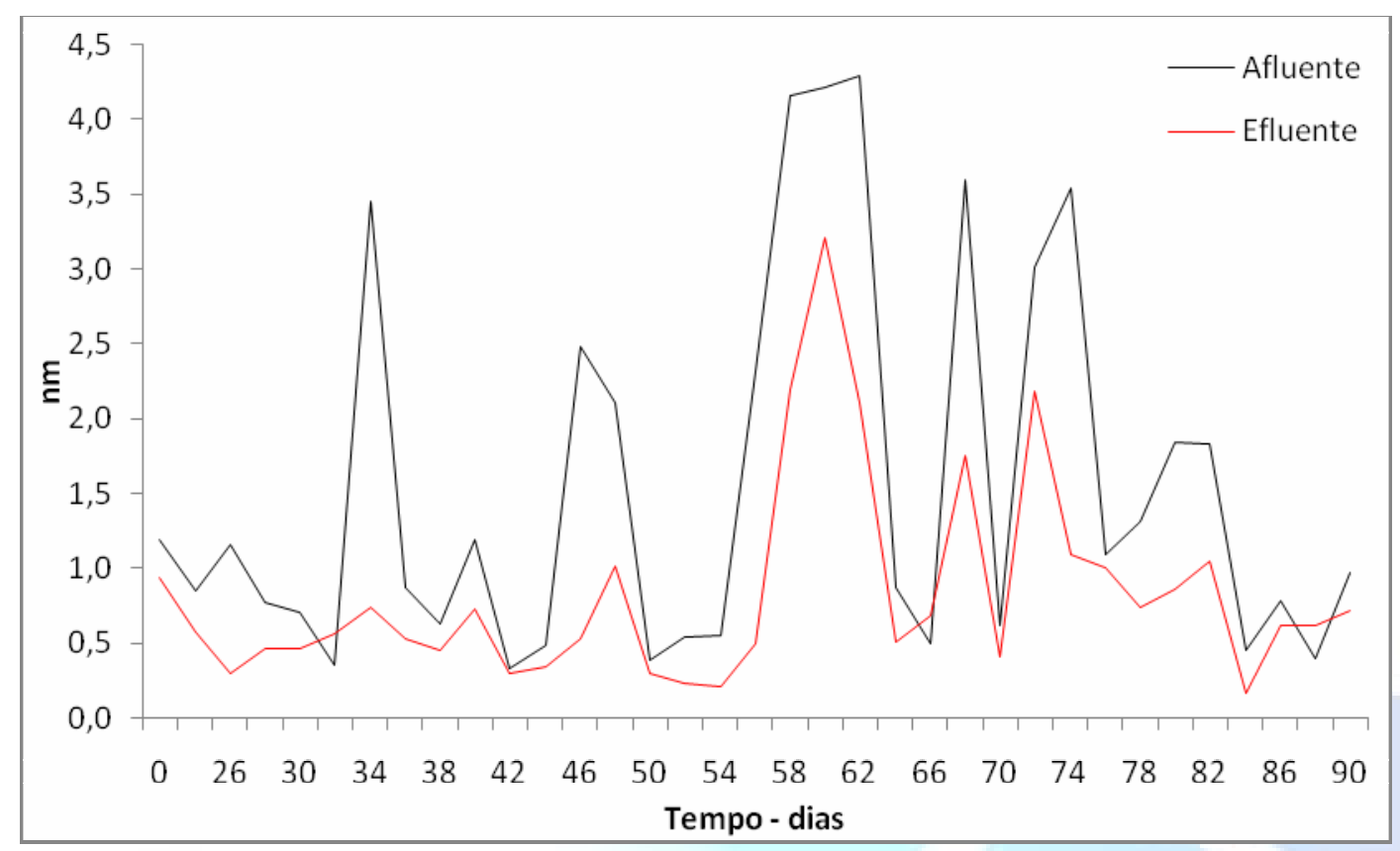

Figura 2. Evolução do parâmetro índice de cor.

\subsection{Remoção de DQO e avaliação das cargas orgânicas}

A concentração de matéria orgânica é alta nos efluentes vinícolas, com valores médios de DQO que podem atingir 15.000 a $20.000 \mathrm{mg} \mathrm{L}^{-1}$ (RODRIGUES et al., 2008). As concentrações observadas nas descargas variam muito de uma cantina para outra. Durante o monitoramento, a eficiência na remoção de DQO variou constantemente atingindo desde $43 \%$ redução, no $28^{\circ}$ dia de monitoramento, até $97 \%$, ocorrido no $70^{\circ}$ dia de monitoramento. Porém a média foi de $78,5 \%$ de eficiência, Tabela 1. Pela tabela nota-se um elevado desvio padrão, isto se deve a variabilidade da origem do efluente, pois para cada processo que a vinícola trabalha, gera-se um efluente diferente (FLANZY, 2000).

Tabela 1 - Desempenho do processo de tratamento de DQO e sólidos suspensos.

\begin{tabular}{ccccc}
\hline Constituinte & \multicolumn{2}{c}{$\mathrm{DQO}\left(\mathrm{mg} \mathrm{L}^{-1}\right)$} & \multicolumn{2}{c}{ Sólidos suspensos $\left(\mathrm{mg} \mathrm{L}^{-1}\right)$} \\
\cline { 2 - 5 } Valor médio & Afluente & Efluente & Afluente & Efluente \\
Desvio Padrão & 18755,56 & 4029,66 & 235,15 & 93,87 \\
Eficiência & $\pm 10648,16$ & $\pm 3732,86$ & $\pm 247,29$ & $\pm 63,70$ \\
\hline
\end{tabular}

Os resultados obtidos foram semelhantes ao estudo realizado por Ortigara (2008), que encontrou média de remoção de DQO para efluente vinícola tratado em reator BAS, na faixa de $87 \%$ durante a safra e $90 \%$ na entressafra.

A remoção dos sólidos suspensos ocorreu de forma eficiente para o BAS, atingindo $60,1 \%$ de redução. No entanto, para o BAS usado como único tratamento, o 
afluente deve ter baixa concentração de sólidos. Segundo Jordão e Pessoa (2005), essa concentração deve ser menor que $120 \mathrm{mg} . \mathrm{L}^{-1}$. No experimento o afluente apresentou média de sólidos suspensos de $235,15 \mathrm{mg} \mathrm{L}^{-1}$.

\subsection{Potencial Hidrogeniônico, Oxigênio Dissolvido, Condutividade e Cor verdadeira}

A condutividade é um parâmetro que pode indicar o impacto ambiental, quando este se apresenta acima de $100 \mu \mathrm{Scm}^{-1}$, para um efluente não tratado. (CETESB, 2008). Na Figura 3, são apresentados os valores obtidos. Nota-se que a condutividade manteve-se abaixo dos $5 \mu \mathrm{Scm}^{-1}$, indicando baixo potencial de impacto ambiental em termos de condutividade elétrica.

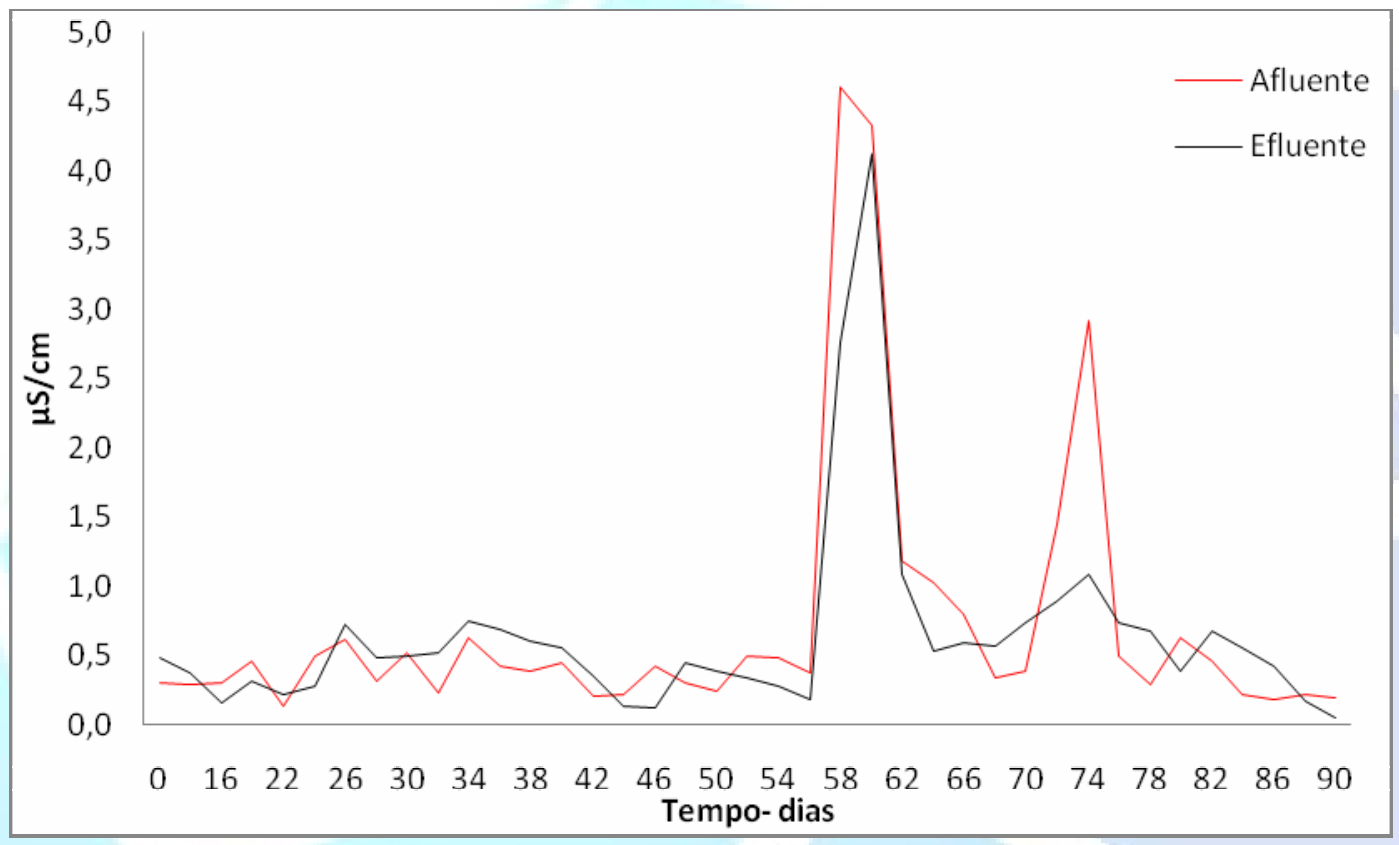

Figura 3. Evolução da condutividade elétrica no reator BAS

$\mathrm{O}$ efluente vinícola caracteriza-se por apresentar $\mathrm{pH}$ entre 4 e 5 , devido a presença de ácidos orgânicos como: ácido cítrico, ácido tartárico, ácido málico, ácido láctico e ácido acético (KIRZNHER, ZIMMELS e SHRAIBER, 2008). O monitoramento do $\mathrm{pH}$ e alcalinidade no afluente e no efluente, dados não mostrados, apresentaram resultados abaixo do que é considerado ideal, porém não foram feitas intervenções químicas para otimizar a eficiência do tratamento. A turbidez foi um interferente na avaliação da cor verdadeira, muitas vezes elevada mesmo após a preparação das amostras. A turbidez obteve valor médio de 22,3 UNT, para o efluente do reator. Durante o processo de monitoramento, ocorreu uma gradual diminuição do oxigênio dissolvido no afluente quando este se encontrava no reator. Tal observação pode ser resultado do processo gradual de geração de biofilme, como também por conta da evolução da cadeia hierárquica dos microorganismos, ocorrendo maior consumo de oxigênio (REIS, 2007). 
O efluente vinícola é caracterizado por conter substâncias corantes, como as antocianinas (ARVANITOYANNIS, LADAS e MAVROMATIS, 2006). A antocianina é um composto extraído da casca da uva, uma substância indicadora que muda de tonalidade em função do $\mathrm{pH}$. Mudanças estruturais ocorrem com a variação do $\mathrm{pH}$ e são responsáveis pelo aparecimento das espécies com colorações diferentes (TERCI e ROSSI, 2002). Na remoção da cor, o BAS não apresentou eficiência, como demonstra a Figura 4. A remoção média de cor foi de $47,4 \%$, com valores médios para o efluente de 440,3 $\mathrm{mg} \mathrm{Pt} \mathrm{L}^{-1}$.

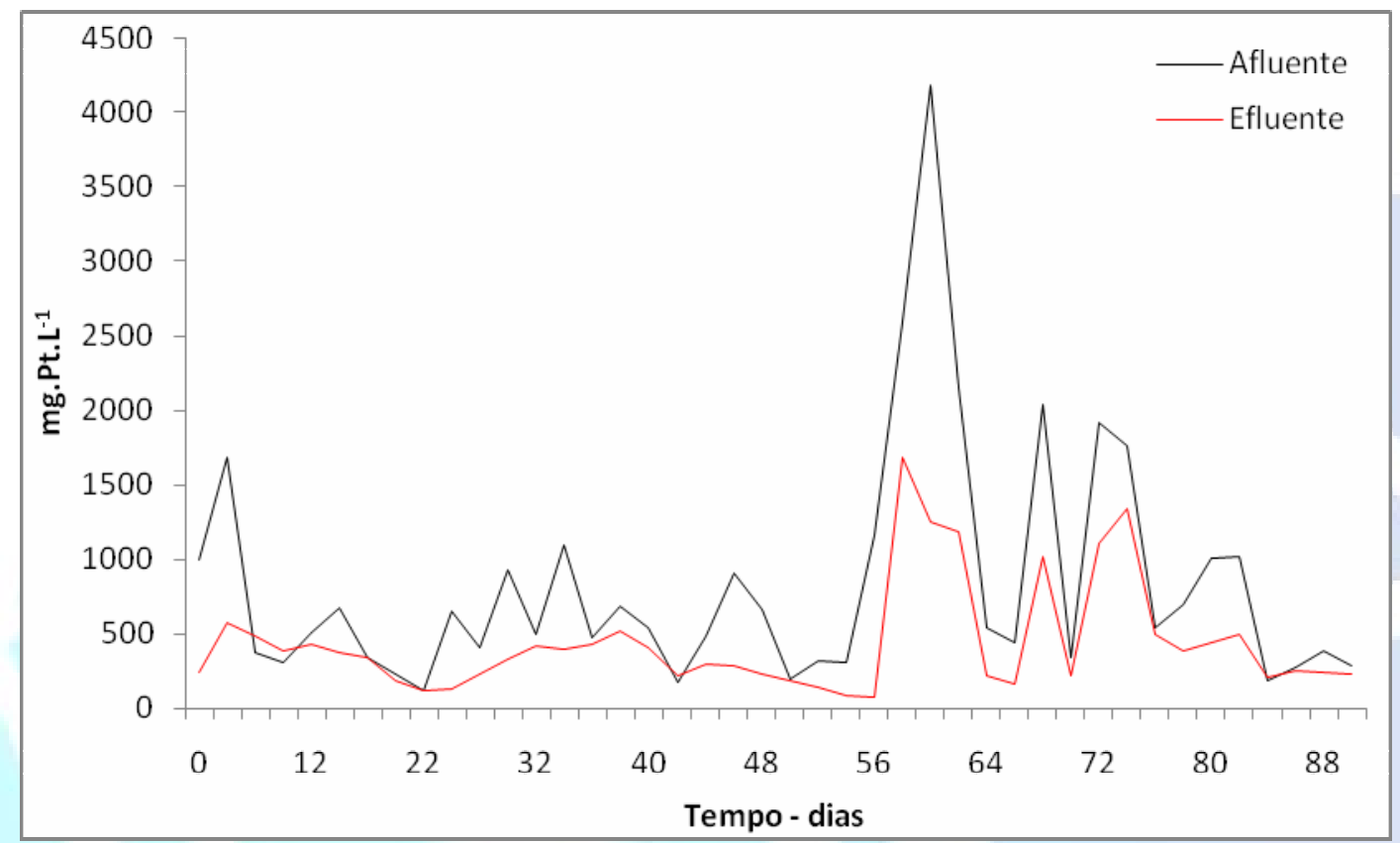

Figura 4. Comportamento do parâmetro cor

3.3. Remoção de nitrogênio, fósforo reativo e processo de nitrificação

A remoção de fósforo reativo em reatores com leito suporte pode ocorrer, dentre outras formas, pela via biológica e pela adsorção ao meio suporte. A Figura 5 demonstra o comportamento do fósforo reativo, que apresentou redução até o $56^{\circ}$ dia de monitoramento, com percentual médio de $67 \%$. Porém, a partir do $70^{\circ}$ dia, as concentrações de fósforo no afluente sempre foram maiores que as concentrações no efluente. Isto pode representar somente a acumulação do constituinte nos primeiros momentos de monitoramento, para posterior liberação deste a partir de certo período. (BITTON, 2005; BEI e TENGRUI, 2008). 


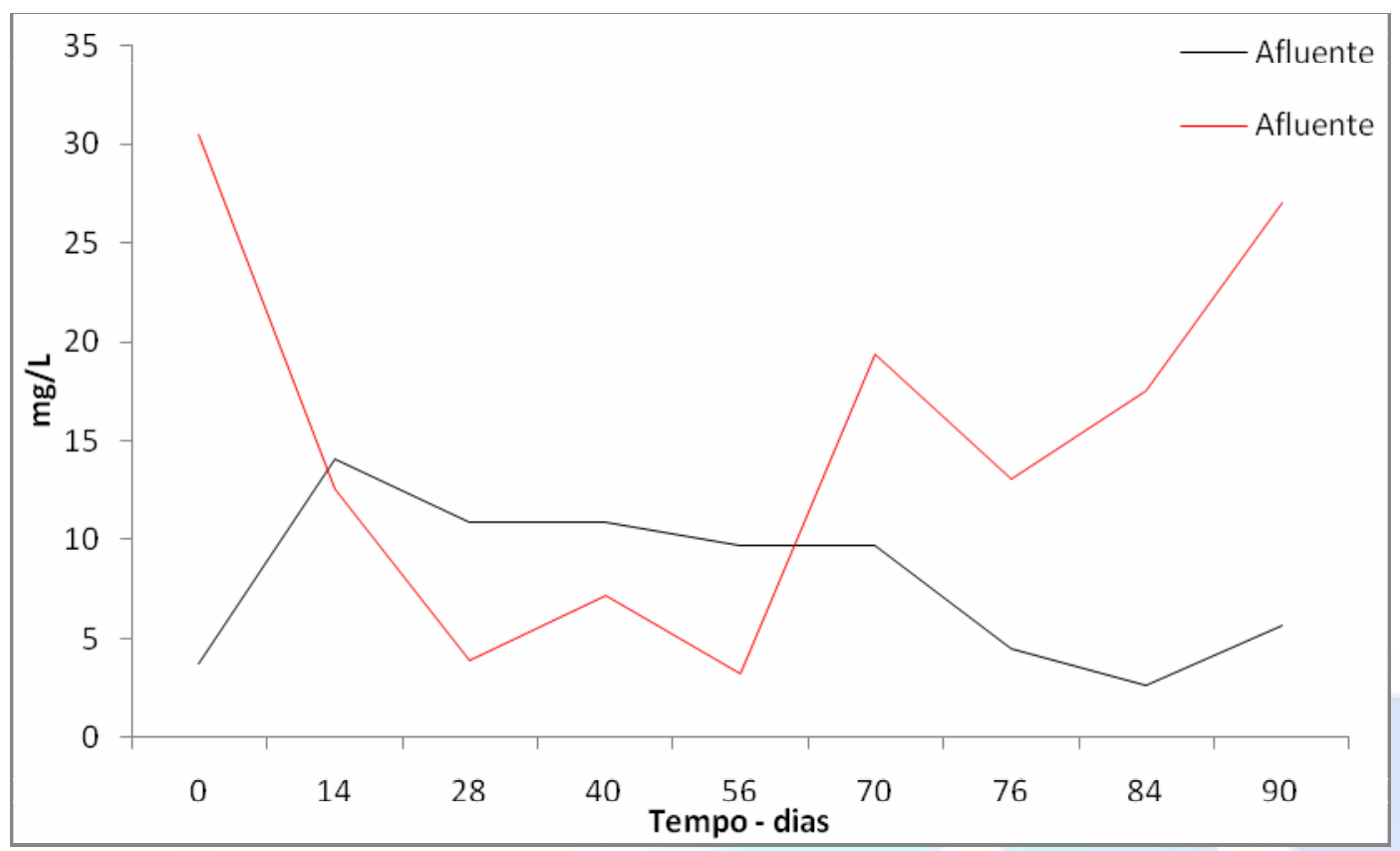

Figura 5. Evolução do fósforo reativo

As condições de efluentes vinícolas para o crescimento de bactérias nitrificantes não são ideais, devido o intervalo de $\mathrm{pH}$ permanecer entre 6,5 e 9,0, (LIMA, 2006). As bactérias heterotróficas em geral convivem com bactérias nitrificantes autotróficas que degradam compostos orgânicos. Porém, competem por espaço e oxigênio no biofiltro, contendo alta carga orgânica, e consequentemente inibindo a nitrificação (DAVIDSON, HELWIG e SUMMERFELT, 2008). Os resultados obtidos apresentaram, no efluente do reator, média de nitrogênio amoniacal de $1,34 \mathrm{mg} \mathrm{L}^{-1}$, com eficiência média de remoção de $37 \%$. Fontana et al. (2007), encontraram eficiências médias de remoção de nitrogênio amoniacal de $80 \%$ e $90 \%$ para dois BAS configurados como pós-tratamento com esgoto sanitário. Tais resultados podem sugerir que outros interferentes podem ter agido no processo de nitrificação monitorado nesta pesquisa.

\subsection{Antocianinas, Polifenóis e Taninos Totais}

A recuperação de compostos como as antocianinas, polifenóis e taninos (Tabela 2) poderiam trazer benefícios econômicos à indústria, além disso, diminuiria o potencial de poluição dos resíduos gerados durante o processo produtivo, tornando a produção de vinho mais limpa e ambientalmente mais correta.

Tabela 2 - Determinação de antocianinas, polifenóis e taninos totais.

\begin{tabular}{ccccccc}
\hline \multirow{2}{*}{ Constituinte } & \multicolumn{2}{c}{ Antocianinas $\left(\mathrm{mg} \mathrm{L}^{-1}\right)$} & \multicolumn{2}{c}{ Polifenóis $\left(\mathrm{mg} \mathrm{L}^{-1}\right)$} & \multicolumn{2}{c}{ Taninos $\left(\mathrm{g} \mathrm{L}^{-1}\right)$} \\
\cline { 2 - 7 } Vfluente & Efluente & Afluente & Efluente & Afluente & Efluente \\
Valor Médio & 349,64 & 267,28 & 990,98 & 634,85 & 3,01 & 1,79 \\
Des. Padrão & $\pm 597,79$ & $\pm 463,12$ & $\pm 702,88$ & $\pm 514,08$ & $\pm 3,78$ & $\pm 2,50$ \\
Eficiência & - & $23,55 \%$ & - & $35,93 \%$ & - & $40,53 \%$ \\
\hline
\end{tabular}


Dentre os compostos que fazem parte do grupo dos polifenóis, existem as antocianinas, as flavonas e os flavonóis, além destes, as uvas e os vinhos contêm uma série de compostos fenólicos, sendo que os teores totais de compostos fenólicos são maiores nas uvas que nos vinhos (ARVANITOYANNIS; LADAS; MAVROMATIS, 2006). Os compostos fenólicos são tóxicos ao meio ambiente aquático, podendo provocar a morte de peixes, mesmo em concentrações na faixa de $1,0 \mathrm{mg} \mathrm{L}^{-1}$. Em concentrações inferiores a $1,0 \mathrm{mg} \mathrm{L}^{-1}$, eles são tóxicos também para outras espécies biológicas, uma vez que destroem o delicado balanço ambiental aquático. Dentre os compostos fenólicos, os que possuem estrutura mais complexa, são frequentemente mais tóxicos (BRITO e RANGEL, 2008). Durante o monitoramento, foram avaliadas as concentrações de polifenóis no afluente e efluente, para determinar a eficiência do BAS na remoção destes. Conforme a Figura 6, o BAS obteve eficiência de 37,1\%, na remoção de polifenóis totais, apresentando, normalmente, comportamento de redução destes compostos.

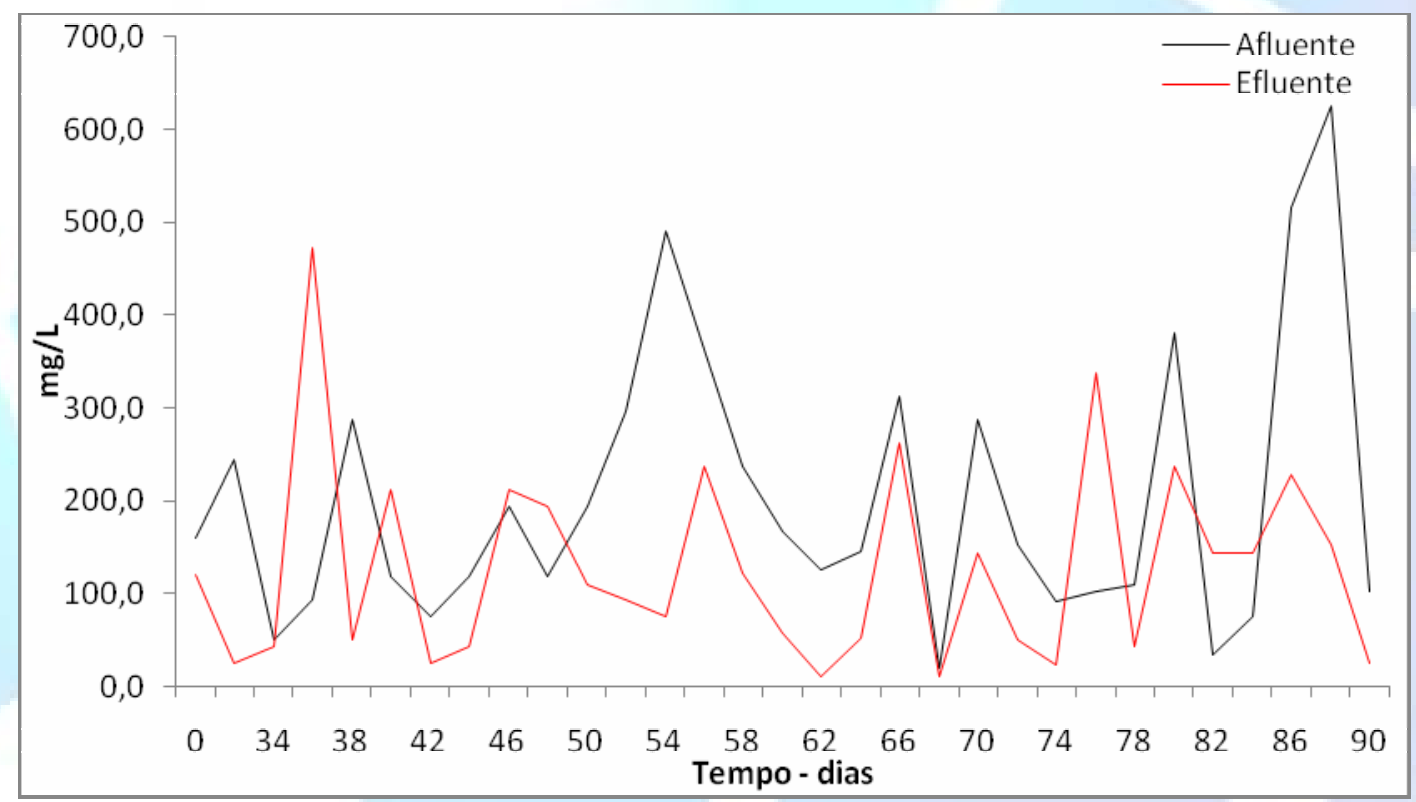

Figura 6. Evolução dos polifenóis totais

\section{CONCLUSÕES}

Os resultados foram satisfatórios, atingindo eficiência significativa para um tratamento unitário. O biofiltro aerado submerso, configurado com meio suporte de rolhas de cortiça, alcançou eficiência média de 78,5\% de remoção de DQO. O processo de nitrificação, transformação de amônia em nitrito, foi observado no reator, indicando uso potencial do BAS neste tipo de tratamento. Não ocorreu remoção de fósforo reativo no reator.

Estudos complementares devem ser realizados a fim de caracterizar melhor o tempo de detenção hidráulica para a operação no tratamento de efluente vinícola. 
O monitoramento de compostos com potencial de reuso na indústria buscou apresentar uma possibilidade de melhoria à indústria viticultora, caracterizando a recuperação de compostos como as antocianinas, taninos e os polifenóis totais.

\section{REFERÊNCIAS}

APHA - AMERICAN PUBLIC HEALTH ASSOCIATION -. Compendium of methods for the microbiological examination of food. 4th ed, Washington, D.C, 2001.

ARVANITOYANNIS, I; LADAS, D; MAVROMATIS. Potential uses and applications of treated wine waste: a review. International journal of food science and technology, London, v.41, p.475-487, 2006.

BEI, Z.; TENGRUI, L. Transformation of phosphorus in intermittent aerated biofilter under aerobic continuous feeding with long backwashing intervals. Journal of Hazardous Materials, Amsterdam, v.156, p.267-276, 2008.

BITTON, G. Wastewater microbiology. $3^{\text {rd }}$, ed. Hoboken: John Wiley e Sons, New Jersey, 2005. $746 \mathrm{p}$.

BORIES, A.; GUILLOT, J.M.;YANICK, S.; COURDERC, M.; LEMAIRE, S. A.; KREIM, V.; BRITO, F. A de. Síntese Anual da Agricultura de Santa Catarina, 2007, p.1138.

BRITTO, J. M.; RANGEL, M. C. Processos avançados de oxidação de compostos fenólicos em efluentes industriais. Química Nova, São Paulo, v. 31, p.114-122, 2008.

CETESB - COMPANHIA DE TECNOLOGIA DE SANEAMENTO AMBIENTAL. Variáveis de qualidade das águas. Disponível em

$<$ http://www.cetesb.sp.gov.br/Agua/rios/variaveis.asp>Acesso em: 19 fev. 2008.

DAVIDSON, J; HELWIG, N.; SUMMERFELT, S. Fluidized sand biofilter used to remove ammonia, biochemical oxigen demand, total coliform bactéria and suspend solids from na intenseve aquaculture effluent. Aquacultural Engineering, Amsterdam, v. 39, n. 1, p. 46-50, 2008.

FONTANA, H.; NETO, A.P.O.; DANIEL, L.A.; CARVALHO, O.J. Desempenho técnico de biofiltro aerado submerso preenchido com carvão granular utilizado no pós-tratamento de esgoto sanitário. In: $24^{\circ}$ CONGRESSO BRASILEIRO DE ENGENHARIA SANITÁRIA E AMBIENTAL, v.24, p. 1-13, Belo Horizonte, 2007. 
FLANZY, C. Enología: Fundamentos científicos y tecnológicos. 1. ed. Madrid: Ediciones Mundi - Prensa, 2000, 783p.

JORDÃO, E. P.; PESSOA, C. A. Tratamento de esgotos domésticos. 4. ed. Rio de Janeiro; SEGRAC, 2005, 932 p.

KIRZNHER, F.; ZIMMELS, Y.; SHRAIBER, Y. Combined treatment of highly contaminated winery wastewater. Separation and Purification Technology, Amsterdam, v.63, n.1, p.38-44, 2008.

LIMA, A.B. B. Pós-tratamento de efluente de reator anaeróbio em sistema seqüencial constituído de ozonização em processo biológico aeróbio. 2006. 99f. Dissertação (Mestrado em Hidráulica e Saneamento) - Departamento de Hidráulica e Saneamento. Escola de Engenharia de São Carlos. Universidade de São Paulo, São Paulo, 2006.

ORTIGARA, A. R. C., Caracterização do efluente de uma vinícola na região do vale do rio do peixe/SC e avaliação do seu tratamento por biofiltro aerado submerso. 2008.143f. Dissertação (Mestrado em Engenharia Ambiental) - Centro Tecnológico - Universidade Federal de Santa Catarina, Florianópolis, 2008.

REIS, G. G. dos. Influência da carga orgânica no desempenho de reatores de leito móvel com biofilme (MBBR). 2007.134f. Dissertação. (Mestrado em Ciências em Engenharia Química) - COOPE - Universidade Federal do Rio de Janeiro, Rio de Janeiro, 2007.

RIBÉREAU-GAYON, P.; DUBOURDIEU,D.; DONÉCHE,B.; LONVAUD, A. Traité d'enologie: Microbiologie du vin vinifications. Paris: Dunod:, 2004, 617p.

RODRIGUES, A.C.; OLIVEIRA, J. M.; OLIVEIRA, J. A.; PEIXOTO, J.; NOGUEIRA, R.; BRITO, A. G.Tratamento de efluentes vitivinícolas: um caso de estudo na região dos vinhos verdes. Indústria e Ambiente, Lisboa, v.40,p. 20-25, 2006. Disponível em < http://repositorium.sdum.uminho.pt/handle/1822/5877>. Acesso em: 25 Jan. 2008.

TEIXEIRA, R. M. Remoção de nitrogênio de efluentes da indústria frigorífica através da aplicação dos processos de nitrificação e desnitrificação em biorreatores utilizados em um sistema de lagoas de tratamento. 2006. 154f. Tese (Doutorado em Engenharia Química) - Departamento de Engenharia Química Universidade Federal de Santa Catarina, Florianópolis, 2006. 
TERCI, D. B. L.; ROSSI, A. V. Indicadores naturais de pH: usar papel ou solução. Química Nova, São Paulo, v. 25, p. 684-688, n. 4, 2002.

TOMASSET, L.U. Enologia: Fundamentos científicos y tecnológico. Química Enologica, Madrid: Ediciones Mundi-Prensa, 1998, 400p. 